\title{
AMYOTROPHIC LATERAL SCLEROSIS
}

\section{Combined nutritional, respiratory and functional assessment}

\author{
Luciano Bruno de Carvalho Silva', Lucia Figueiredo Mourão ${ }^{2}$, Ariovaldo Armando Silva ${ }^{3}$ \\ Núbia Maria Freire Vieira Lima ${ }^{4}$, Sara Regina Almeida ${ }^{4}$, Marcondes C. Franca Jr ${ }^{5}$, \\ Anamarli Nucci ${ }^{6}$, Jaime Amaya-Farfán ${ }^{7}$
}

\begin{abstract}
Objective: To establish correlations between nutritional, functional and respiratory indices of patients with amyotrophic lateral sclerosis (ALS). Method: Twenty patients (13 appendicular - GA and 7 bulbar GB) were included in the multidisciplinary study at the Neurological Clinic Ambulatory of the University of Campinas Hospital. Results: Among the GA type significant correlation was observed between maximal inspiratory (MIP) and expiratory (MEP) pressure $(r=-0.76)$, MEP and pulse oxymetry $(r=0.58)$, MIP and percent weight loss (\%WL; $r=0.59$ ), and between MIP, total and subscale respiratory scores (ALSFRS-R) with \%WL. With regard to the GB, correlation was found between MEP and body mass index (BMI) ( $r=0.97)$. In both GA and GB correlations were noticed between the $\mathrm{BMI}$ and the variables mass ( $\mathrm{kg})$, fat $(\%)$, arm and wrist circumference $(\mathrm{cm})$, and tricipital, subscapular and supra-iliac skinfolds $(\mathrm{mm})$, as well as the arm muscle circumference $(\mathrm{cm})$ and fatty arm muscular area $\left(\mathrm{mm}^{2}\right)$. Conclusion: It is suggested that the application of simple anthropometric measurements could be useful in routine monitoring of patients with ALS.
\end{abstract}

KEY WORDS: amyotrophic lateral sclerosis, nutritional support, respiratory tests, ALSFRS scale.

Esclerose lateral amiotrófica: correlações dos indicadores da avaliação nutricional, funcional e respiratória

Resumo - Objetivo: Correlacionar os indicadores utilizados na avaliação nutricional, funcional e respiratória de indivíduos com esclerose lateral amiotrófica (ELA). Método: Vinte pacientes (13 apendiculares - GA e 7 bulbares - GB) foram incluídos no estudo usando parâmetros nutricionais, respiratórios e escala funcional (ALSFRSR). Resultados: Entre os pacientes do $\mathrm{GA}$, as correlações observadas foram: pressão inspiratória máxima $\left(\mathrm{PI}_{\max }\right)$ e expiratória máxima ( $\left.\mathrm{PE}_{\max }\right)(\mathrm{r}=-0,76) ; \mathrm{PE}_{\max }$ e oximetria de pulso $(\mathrm{r}=0,58) ; \mathrm{PI}_{\max }$ e porcentagem de perda de peso (\%PP) (r=0,59); e entre $\mathrm{Pl}_{\max }$, escore ALSFRS-R com \%PP. No GB, houve correlação entre MEP e índice de massa corporal (IMC) ( $r=0,97)$. Em GA e GB, observaram-se correlação entre IMC e as variáveis: massa, gordura (\%), circunferência braquial e punho, pregas cutâneas tricipital, subescapular e supra-ilíaca, circunferência muscular do braço $(\mathrm{cm})$, área muscular gordurosa do braço $\left(\mathrm{mm}^{2}\right)$. Conclusão: Sugere-se a aplicação deste conjunto de medidas durante a evolução clínica de indivíduos com ELA.

PALAVRAS-CHAVE: esclerose lateral amiotrófica, suporte nutricional, testes respiratórios, escala ALSFRS-R.

Amyotrophic lateral sclerosis (ALS) is a neurodegenerative condition characterized by progressive weakness and amyotrophy due to degeneration of motor neurons. ALS patients usually exhibit progressive disability that requires a multidisciplinary therapeutic approach. Bulbar dysfunction resulting from damage either to corticobulbar pathway or brainstem motor nuclei is one of the most important clinical problems encountered in $\mathrm{ALS}^{1,2}$. It is re- lated to dysphagia and respiratory complications, which are major causes of morbidity and mortality in ALS. Decline in respiratory function occurs as disease progresses, due to diaphragmatic fatigue and weakness, atelectasis and broncoaspiration ${ }^{3,4}$.

Malnutrition as a consequence of dysphagia may further worsen respiratory function and shorten survival. Abnormalities of the control and strength of the laryngeal

\footnotetext{
'MD, Food and Nutrition Department, School of Food Engineering (FEA), NEPA (Center for Food Security Studies) of the University of Campinas, Campinas SP, Brazil (UNICAMP), and Federal University of Alfenas, MG, Brazil (UNIFAL-MG); ${ }^{2}$ MD, PhD, Speech Pathologist Medical School (FCM/UNICAMP); ${ }^{3}$ MD, FCM-UNICAMP Otorrionolaringology FCM/UNICAMP; ${ }^{4}$ Physiotherapeutic Dept. of Neurology FCM/UNICAMP; ${ }^{5}$ Neurologist Ambulatory Neuromuscular Diseases HC/UNICAMP; ${ }^{6} \mathrm{MD}$, FCM/UNICAMP, Ambulatory Neuromuscular Diseases HC/UNICAMP; ${ }^{7}$ Full Prof. FEA/UNICAMP, NEPA/UNICAMP. This study was supported by CNPq - Conselho Nacional de Desenvolvimento Científico, Brazil (PhD Grant to LBCS).
}

Received 18 December 2007, received in final form 28 March 2008. Accepted 23 April 2008.

Dr. Luciano Bruno de Carvalho Silva - Rua Monteiro Lobato 80 - 13083-862 Campinas SP - Brasil. E-mail: luciano@unifal-mg.edu.br 
and pharyngeal muscles may cause upper airway obstruction increasing resistance to airflow ${ }^{4}$. Although ALS patients with bulbar involvement suffer from more severe swallowing problems, "non-bulbar" ALS patients may also have dysphagia ${ }^{3}$.

There are few data devoted to the combined assessment of nutritional and respiratory status of ALS patients. In this setting, we studied the nutritional, respiratory and functional profile of a cohort of ALS patients. We looked for correlations between these variables in order to identify determinant factors in the severity of the disease.

\section{METHOD}

This is a cross-sectional descriptive study of 20 ALS patients regularly followed at the Neuromuscular Outpatient Clinic of Campinas University Hospital (UNICAMP). The study was approved by the ethics committee of the School of Medical Sciences - UNICAMP and all patients accepted a written consent.

Patients meeting the El-Escorial criteria ${ }^{5}$ for defined ALS, either with bulbar or appendicular predominance, regularly followed in the Clinic and without intervening neurological illnesses were included in the study. At the time of enrollment, none of the selected patients presented active heart or lung disease, including pneumonia. They were included regardless of gender or duration of disease. Patients with nasogastric tube or gastrostomy, or on assisted mechanical ventilation were excluded.

\section{Nutritional assessment}

We employed the following measures to assess body composition:

Body weight $(\mathrm{kg})$ measured in a platform scale (Toledo do Brasil). Ideal body weight for each individual was defined according to tables of the Metropolitan Life Insurance Company ${ }^{6}$.

Height $(\mathrm{m})$ measured in meters. In bedridden or wheel-chair bound patients, it was estimated according to Chumlea et al. ${ }^{7}$.

Body mass index ${ }^{8}$ (BMI) defined as the ratio of body weight $(\mathrm{kg}) /$ squared height $\left(\mathrm{m}^{2}\right)$ and expressed as $\mathrm{kg} / \mathrm{m}^{2}$.

Midarm circumference (MAC) was expressed in $\mathrm{cm}$ and measured at the mid-point between the olecranon and the clavicular acromium?.

Wrist circumference (WC) also expressed in cm was measured at the level of radial and ulnar styloid processes around the wrist $^{10}$.

Skinfolds (SF): triciptal (TSF), biciptal (BSF), supra-iliac (SISF) and subscapular (SESF) skinfolds were measured in $\mathrm{mm}$ in order to classify ALS patients according to estimates of relative body fat ${ }^{11}$.

Midarm muscle circumference (MAMC), arm muscle area (AMA) and arm fat area (AFA) obtained from MAC and TSF ${ }^{10}$.

Percentage of weight loss (\%WL) was determined as follows:

$$
\% W L=\frac{\text { usual weight }- \text { measured weight }}{\text { usual weight }} \times 100
$$

Usual weight $=$ regular weight reported by the patient before the disease onset; Measured weight = weight of the patient at the time of clinical evaluation.

Individuals with \%WL ranging from 5 to $10 \%$ were considered to have malnutrition; those with \%WL above $10 \%$ had severe malnutrition ${ }^{12}$.

Classification of nutritional status: we employed the protein-caloric malnutrition score $(\mathrm{PCMS})^{13}$ to classify nutritional status of patients. PCMS is based on $\%$ ad (per-cent adequacy); IW (ideal weight); TSF (triceps skinfold); MAC (midarm circumference); MAMC (midarm muscle circumference) and calculated as follows:

$P C M S=\frac{\% a d I W+\% a d T S F+\% a d M A C+\% a d M A M C+\% a d A M A}{\text { Number of parameters }}$

Amyotrophic lateral sclerosis functional rating scale

Revised (ALSFRS-R) $)^{14}$. This is a questionnaire-based scale for activities of daily living. This scale contains 12 items grouped into three domains that encompass appendicular function (gross and motor tasks), bulbar and respiratory function. Each item has a 5 -point scale ( 0 for unable. 4 for normal) and scores ranging from 0 to 48. Low scores denote a serious disease status.

\section{Respiratory assessment}

The strength of inspiratory and expiratory muscles was assessed through maximum inspiratory and expiratory pressures (MIP and MEP, respectively), obtained from residual volume and total lung capacity. A Marshall Town ${ }^{\circledR}$ device (Black and Hyatt) ${ }^{15}$ was used to perform the measurements. While seated and using a nasal clamp, patients were instructed to breath as deep as possible in order to determine MIP e MEP. These procedures were consecutively repeated 3 times each. Thirty seconds apart, and the highest values were recorded for analysis. Individuals underwent spirometry in a seated position to quantify dynamic respiratory function. Forced vital capacity (FVC) expressed either as an absolute value or as percentage of the predicted value for age and sex, was recorded for all patients. Pulse oxymetry was accomplished with a Morvia 1001 device.

The patients were evaluated by an interdisciplinary group. The nutritional assessment was done by a nutritionist and the ALSFRS-R and respiratory assessment by physiotherapeutics.

\section{Statistical analysis}

We used Kolmogorov-Smirnov test to evaluate whether studied variables presented normal distribution. Pearson and Spearman correlation coefficients were employed to analyze normally and non-normally distributed variables, respectively. Significance level was set at 0.05 . Spearman coefficients were considered as follows: 0 to 0.19 - weak correlations; 0.2 to 0.39 - mild correlations; 0.4 to 0.59 - moderate correlations; 0.6 to 0.79 - important correlations; 0.8 to 1 - almost perfect correla- 
Table 1. Demographic data $(n=20)$.

\begin{tabular}{|c|c|c|c|c|}
\hline & \multicolumn{2}{|c|}{ Bulbar group $(n=7)$} & \multicolumn{2}{|c|}{ Appendicular group $(n=13)$} \\
\hline & Mean \pm SE & $\min -\max$ & Mean \pm SE & $\min -\max$ \\
\hline Gender (Male/Female) & \multicolumn{2}{|c|}{$4 / 3$} & \multicolumn{2}{|c|}{$12 / 1$} \\
\hline Age & $50.6 \pm 9.9$ & $36-69$ & $45.8 \pm 12.6$ & $32-69$ \\
\hline Total ALSFRS-R ${ }^{1}$ & $26.1 \pm 1.5$ & $12-45$ & $34.3 \pm 7.6$ & $16-43$ \\
\hline Bulbar & $7.14 \pm 2.3$ & $4-10$ & $10.3 \pm 1.6$ & $7-12$ \\
\hline Appendicular (gross and fine tasks) & $8.14 \pm 8.5$ & $1-23$ & $12.8 \pm 6.14$ & $1-22$ \\
\hline Respiratory & $10.8 \pm 1.8$ & $7-12$ & $11.2 \pm 1.6$ & $6-12$ \\
\hline Oxymetry & $0.94 \pm 0.03$ & $0.86-0.97$ & $0.94 \pm 0.03$ & $0.87-0.99$ \\
\hline $\mathrm{MIP}^{2}$ & $-24.1 \pm 17.7(n=6)$ & $-45 ;-5$ & $-61.6 \pm 33.6$ & $-135 ;-25$ \\
\hline MEP $^{3}$ & $35 \pm 25.4(n=5)$ & $10-70$ & $62.3 \pm 31.4$ & $10-130$ \\
\hline FVC ${ }^{4}$ & $54(n=1)$ & - & $84(n=9)$ & $52-109$ \\
\hline
\end{tabular}

${ }^{1}$ ALSFRS-R, amyotrophic lateral sclerosis functional rating scale; ${ }^{2} \mathrm{MEP}$, maximal expiratory pressure; ${ }^{3} \mathrm{MIP}$, maximal inspiratory pressure; ${ }^{4} \mathrm{FVC} \%$, percentage of forced vital capacity.

Table 2. Correlations of nutritional, functional and respiratory indicators of bulbar and appendicular groups.

\begin{tabular}{|c|c|c|c|c|}
\hline \multirow[t]{2}{*}{ Correlations } & \multicolumn{2}{|c|}{ Bulbar group $(n=7)$} & \multicolumn{2}{|c|}{ Appendicular group $(n=13)$} \\
\hline & r & $\mathrm{p}$-value & r & $\mathrm{p}$-value \\
\hline Time onset ALS $x$ bulbar score ALSFRS-R ${ }^{1}$ & 0.9 & $0.005^{*}$ & -0.04 & 0.88 \\
\hline Time onset ALS $x$ total ALSFRS-R & -0.82 & $0.023^{*}$ & -0.37 & 0.206 \\
\hline Time onset ALS x Oximetry & -0.26 & 0.563 & -0.75 & $0.003^{*}$ \\
\hline Time onset ALS $\times \mathrm{WL}^{2}$ & 0.73 & 0.063 & 0.32 & 0.296 \\
\hline Respiratory score ALSFRS-R x \%WL & -0.33 & 0.436 & -0.59 & $0.042^{*}$ \\
\hline Total ALSFRS-R x \%WL & -0.39 & 0.379 & -0.59 & $0.042^{*}$ \\
\hline MIP $^{3} \times$ Respiratory score ALSFRS-R & 0.18 & 0.72 & -0.65 & $0.016^{*}$ \\
\hline MIP $\times M^{M E P^{4}}$ & -0.66 & 0.219 & -0.76 & $0.002^{*}$ \\
\hline MEP x Oximetry & 0.63 & 0.253 & 0.58 & $0.034^{*}$ \\
\hline MEP $\times \mathrm{BMI}^{5}$ & 0.97 & $0.005^{*}$ & 0.49 & 0.09 \\
\hline
\end{tabular}

${ }^{*} \mathrm{p}<0.05 ;{ }^{1} \mathrm{ALSFRS}-\mathrm{R}$, amyotrophic lateral sclerosis functional rating scale-revised; ${ }^{2} \% \mathrm{WL}$, $\%$ of weight loss; ${ }^{3} \mathrm{MEP}$, maximal expiratory pressure; ${ }^{4} \mathrm{MIP}$, maximal inspiratory pressure; ${ }^{5} \mathrm{BMI}$, body mass index.

tions $^{16}$. SPSS for Windows version 15.0 was employed in the statistical analysis ${ }^{17}$.

\section{RESULTS}

Table 1 shows the demographic data of the patients enrolled in the study. In 13 patients, limbs were predominantly involved (appendicular ALS - GA), whereas in another 7, was predominantly bulbar (GB). We did not find significant differences regarding duration of disease or age between these groups (Table 1). Patients in the GB group had lower ALSFRS-R scores in comparison to patients in the GA group ( 54 vs $71 \%$ of maximum score).

Correlation coefficients of nutritional (\%WL, BMI), functional (ALSRFS-R score) and respiratory (MIP, MEP, pulse oxymetry and FVC) parameters in groups GA and GB are displayed on Table 2. We did not find significant association between \%FVC and MIP, MEP and oxymetry ( $p=0.158 ; 0.83 ; 0.246$, respectively) in the GA group. In the GB group, however, only one patient was able to perform spirometry, thus precluding the analysis of correlations. In the GA group, there was a significant correlation between MIP and MEP ( $p=0.002$ ), as well as MEP and pulse oxymetry $(p=0.034)$. Similar findings were not identified in the GB group, since results of respiratory function were less reliable in that group due to the severe weakness of oropharyngeal muscles.

Anthropometric data are shown in Table 3. Nutritional profiles of patients in both groups was similar. There were not significant differences between the GA and GB groups regarding nutritional profiles.

BMI was significantly associated with most nutritional markers both in patients of the GA and GB groups (Table 4). 
Table 3. Anthropometric profile of patients with ALS according to the predominance symptoms.

\begin{tabular}{|c|c|c|c|c|c|}
\hline & \multicolumn{2}{|c|}{ Bulbar group $(n=7)$} & \multicolumn{2}{|c|}{ Appendicular group $(n=13)$} & \multirow[t]{2}{*}{$\mathrm{p}^{*}$} \\
\hline & Mean & $\mathrm{SE}^{*}$ & Mean & $\mathrm{SE}^{\star}$ & \\
\hline Height (m) & 1.684 & 0.007 & 1.71 & 0.004 & 0.156 \\
\hline Mass (kg) & 63.99 & 1.38 & 68.51 & 1.12 & 0.356 \\
\hline Body mass index $\left(\mathrm{kg} / \mathrm{m}^{2}\right)$ & 21.97 & 0.35 & 23.26 & 0.36 & 0.097 \\
\hline Weight loss (\%) & 17.68 & 1.19 & 13.61 & 0.97 & 0.708 \\
\hline Fat mass (\%) & 25.66 & 0.60 & 23.72 & 0.40 & 0.188 \\
\hline Lean mass (\%) & 83.95 & 0.50 & 83.72 & 0.51 & 0.350 \\
\hline Initial arm circumference $(\mathrm{cm})$ & 25.94 & 0.41 & 26.12 & 0.36 & 0.273 \\
\hline Arm circumference $(\mathrm{cm})$ & 25.74 & 0.39 & 27.46 & 0.36 & 0.061 \\
\hline Initial wrist circumference $(\mathrm{cm})$ & 15.49 & 0.12 & 17.13 & 0.06 & 0.131 \\
\hline Wrist circumference $(\mathrm{cm})$ & 15.36 & 0.11 & 17.68 & 0.08 & 0.536 \\
\hline Tricipital skin fold (mm) & 14.70 & 0.47 & 10.73 & 0.33 & 0.971 \\
\hline Bicipital skin fold (mm) & 9.30 & 0.44 & 6.45 & 0.19 & 0.405 \\
\hline Supra-iliac skin fold (mm) & 16.30 & 0.66 & 16.09 & 0.73 & 0.599 \\
\hline Subescapular skin fold (mm) & 11.10 & 0.36 & 13.32 & 0.32 & 0.117 \\
\hline Sum of all skinfolds (mm) & 51.40 & 1.46 & 46.59 & 1.37 & 0.935 \\
\hline Muscle circumference of the $\operatorname{arm}(\mathrm{cm})$ & 22.22 & 1.77 & 24.13 & 0.28 & 0.438 \\
\hline Muscle area of the arm $(\mathrm{cm})$ & 41.36 & 2.97 & 59.75 & 1.65 & 0.340 \\
\hline Fat area of the arm $(\mathrm{cm})$ & 57.68 & 1.64 & 57.92 & 1.49 & 0.087 \\
\hline
\end{tabular}

$S E^{*}$, standard error; $\mathrm{P}^{*}$, Spearman correlation $(\alpha=5 \%)$.

Table 4. Spearman correlation coefficients of BMI and other nutritional markers according to the predominance symptoms of the disease.

\begin{tabular}{|c|c|c|c|c|}
\hline & \multicolumn{2}{|c|}{ Bulbar group ( $n=7$ ) } & \multicolumn{2}{|c|}{ Appendicular group $(n=13)$} \\
\hline & $r$ & $\mathrm{p}$-value & $r$ & $\mathrm{p}$-value \\
\hline Height (m) & 0.148 & 0.684 & 1.38 & 0.695 \\
\hline Mass (kg) & 0.661 & $0.038^{*}$ & 0.982 & $0.00 *$ \\
\hline Weight loss (\%) & -0.164 & 0.651 & -0.400 & 0.233 \\
\hline Fat mass (\%) & 0.127 & 0.726 & 0.834 & $0.001^{*}$ \\
\hline Lean mass (\%) & -0.733 & 0.016 & -0.955 & $0.00 *$ \\
\hline Arm circumference $(\mathrm{cm})$ & 0.912 & $0.00 *$ & 0.815 & $0.002^{*}$ \\
\hline Wrist circumference $(\mathrm{cm})$ & 0.215 & 0.551 & 0.332 & 0.319 \\
\hline Tricipital skin fold (mm) & 0.209 & 0.562 & 0.701 & $0.016^{*}$ \\
\hline Bicipital skin fold (mm) & -0.038 & 0.918 & 0.424 & 0.194 \\
\hline Supra-iliac skin fold (mm) & 0.535 & 0.111 & 0.748 & $0.009 *$ \\
\hline Subescapular skin fold (mm) & 0.851 & $0.002^{*}$ & 0.814 & $0.002^{*}$ \\
\hline Muscle circumference of the arm $(\mathrm{cm})$ & 0.845 & $0.002^{*}$ & 0.811 & $0.002^{*}$ \\
\hline Muscle area of the arm $(\mathrm{cm})$ & 0.576 & 0.082 & 0.700 & $0.016^{*}$ \\
\hline Fat area of the arm $(\mathrm{cm})$ & 0.891 & $0.001^{*}$ & 0.719 & $0.004^{*}$ \\
\hline
\end{tabular}

Among patients in the GA group, the variable that best correlated to BMI was mass ( $r=0.982$ ), but in the GB group, arm circumference presented the best correlation ( $r=0.912)$.

\section{DISCUSSION}

Survival time is a major endpoint employed in clinical trials for ALS. Overall, mean survival ranges from 2 to 4 years, although there is great variability among patients ${ }^{18}$. Elderly individuals, women and those with predominance bulbar involvement have shorter survival odds after the onset of the disease ${ }^{19}$.

Although FVC has been considered the most reliable 
tool to monitor respiratory function in patients with ALS, it is not as useful to estimate strength of respiratory muscles $^{20,21}$. FVC is not a sufficiently sensitive test to detect early respiratory involvement in ALS, and there is only a weak correlation between FVC and parameters such as MIP and MEP22.

Although respiratory complaints are frequent in ALS, studies on the relationship of dyspnea and objective measurements of respiratory function in the disease are scanty. Melo et al. ${ }^{23}$ reported that severity of dyspnea was related to respiratory muscle weakness expressed as abnormal MIP and MEP. Similarly, Dugan et al. ${ }^{24}$ found reduced values of MIP and MEP in dyspneic ALS patients. Our data are in accordance with those findings since MIP and respiratory scores of ALSFRS-R, which is a reliable marker for dyspnea in ALS, were significantly correlated $(p=0.016)$. These findings suggest that clinical evaluation and MIP may be useful to monitor the loss of respiratory quality in ALS.

Cedarbaum et al..$^{14}$ found that FVC and respiratory scores of ALSFRS-R were related in ALS ( $r=0.53$ e $p=0.0001)$ but this was not replicated in our patients. These authors emphasized that the items dyspnea and orthopnea of ALSFRS-R may be altered in patients with normal FVC. Four patients in the GB group showed respiratory scores below maximum. However, mean FVC was $84 \%$ for patients in the GB group. Therefore, dyspnea in some patients with preserved respiratory reserve may be more closely related to factors such as fatigue and bad conditioning.

Malnutrition in ALS is closely associated to dysphagia and thus an early finding in patients with progressive bulbar palsy occurrance ${ }^{25}$. Due to oro-pharyngeal muscle weakness, measurements such as MIP and MEP are less reliable in those patients. Despite this, MEP and $B M I$ were strongly correlated in patients of the GB group $(p=0.005)$.

Both dysphagia and neurogenic muscle atrophy may contribute to the percent weight loss in $\mathrm{ALS}^{26}$, MIP, ALSFRS-R total score and respiratory sub-score correlated independently with \%WL $(p<0.05)$ in patients of the GA, but not GB group. This may be explained by the more severe muscular atrophy identified in the GA group (FFM\%=79.6 and 84.9 , respectively).

There were no significant differences between the $G A$ and $G B$ groups regarding nutritional profiles. BMI was slightly lower among patients in the GB group, but difference did not reach statistical significance. Our data on body mass, BMI, fat\%, TSF, MAMC, AMA and AFA were also similar to those found by Stanich et al. ${ }^{27}$, in a cohort of patients with ALS from São Paulo (Brazil), suggesting they accurately characterize the disease.
In this series, patients would be classified as eutrophic according to $\mathrm{BMI}$; however, if we take into account the PCMS score, patients would be classified as moderately malnourished (mean PCMS scores of 76.66 and 79.76 in groups GB and GA, respectively). Overall, PCMS is more appropriate than $\mathrm{BMI}$ to characterize nutritional status of patients because it includes separately muscle and adipose mass rather than total body mass. We found high $\% W L$ values, indicating significant differences between the usual weight and the actually measured weight of the patient at clinical evaluation. Percent $\mathrm{WL}$ is a parameter readily determined and useful to assess nutritional status in ALS. BMI should not be the unique marker to assess nutritional status because of the lack of sensitivity to low weight losses, adipose accumulation, lean mass reduction and dehydration, all of which may make it difficult to interpret the results ${ }^{28-30}$.

MAC and WC are frequently used in population studies $^{31}$. In our patients, they were tightly related to BMI. Among patients of the GA group, MAC and WC were parameters smaller at the side initially affected by the disease process (mean difference $=1.34$ and $0.55, p=0.003$ and 0.037 , respectively). Such an asymmetry may be clinically relevant since it may either overestimate or underestimate the actual nutritional needs of the patients (measurements are usually performed on one side). PCMS also helped to accurately perform nutritional classification of patients with ALS, since parameters employed to calculate this score were correlated with BMI.

There was significant correlation between respiratory parameters, namely MIP and MEP, and ALSFRS-R in both groups, GA and GB. As shown in Table 2, BMI and \%WL were also related to the respiratory parameters. In addition, we found significant correlations between BMI and other measures of nutritional status, thus suggesting that these tools might help to prevent morbidity in the disease.

In conclusion, nutritional, functional and respiratory profiles were similar in patients with ALS of either bulbar or appendicular predominance. Nutritional status was tightly related to functional and respiratory disability. Although preliminary, our data indicate that these tools might help to prevent morbidity in the disease.

\section{REFERENCES}

1. Nelson LM, Matkin C, Longstreth WT, Mcguire V. Population - based case - control study of amyotrophic lateral sclerosis in Western Washington State. II. Diet Am J Epidemiol 2000;151:164-173.

2. Kasarskis E, Berryman S, Vanderleest JG, Schneider AR, McClain CJ. Nutritional status of patients with amyotrophic lateral sclerosis: relation to the proximity of death. Am J Clin Nutr 1996;63:130-137.

3. Fattori B, Grosso M, Bongioanni P, et al. Assessment of swallowing by oropharyngoesophageal scintilography in patients with amyotrophic lateral sclerosis. Dysphagia 2006;21:280-286.

4. Hadjikoutis S, Wiles CM. Respiratory complications related to bulbar dysfunction in motor neuron disease. Acta Neurol Scand 2001;103:207-213. 
5. El Escorial revisited: revisited criteria for the diagnosis of ALS.-World Federation of Neurology research group on motor diseases. A consensus conference held at Airlie House. Worrenton 1998;2-4.

6. Grant JP, Custer PB, Thurlow J. Current techniques of nutrition assessment. In Grant JP (ed). Handbook of total parenteral nutrition. Philadelphia: WB Saunders 1980:7-42.

7. Chumlea MAC, Roche AF, Steinbaugh ML. Estimating stature from knee height for persons 60 to 90 years of age. J Am Geriatric Soc 1985;33:116-120.

8. Rio A, Cawadias E. Nutritional advice and treatment by dietitians to patients with amyotrophic lateral sclerosis / motor neurone disease: a survey of current practice in England, Wales, Northern Ireland, and Canada. J Hum Nutr Diet 2007;20:1-13.

9. Callaway CW, Chumlea WC, Bouchard C, et al. Anthropometric standardization reference manual. In Lohman TG, Roche AF, Martorell R. (eds). Circumferences. Champaign: Abridged Edition - Human Kinetics 1991:39-54.

10. Fernandes J Filho. A prática da avaliação física. Rio de Janeiro: Shape, 1999:17-38.

11. Frisancho AR. New norms of upper limb fat and muscle areas for assessment of nutritional status. Am J Clin Nutr 1981;34:540-545.

12. Mahan K, Stump SE. Krause: alimentos, nutrição e dietoterapia. ed. 11. São Paulo: Roca, 2005:535-569.

13. Blackburn GL, Harvey KB. Nutritional assessment as a routine in clinical medicine. Postgrad Med 1982;71:46-63.

14. Cedarbaum JM, Stambler N, Malta E, et al. The ALSFRS-R: a revised ALS functional rating scale that incorporates assessments of respiratory function. J Neurol Sci 1999;169:13-21.

15. Black LF, Hyatt RE. Maximal respiratory pressures: normal values and relationship to age and sex. Am Rev Respir Dis 1969;99:696-702.

16. Landis JR, Koch GG. The measurement of observer agreement for categorical data. Biometrics 1977;33:159-174

17. Norussis MJ. Statistical Package for Social Science (SPSS) for Windows Advanced Statistics Release 15.0. Chicago: SPSS;2006.

18. Magnus T, Beck M, Giess R, Puls I, Naumann N, Toyka KV. Disease progression in amyotrophic lateral sclerosis: predictors of survival. Muscle Nerve 2002;25:709-714.

19. Czaplinski A, Yen AA, Appel SH. Amyotrophic lateral sclerosis: early predictors of prolonged survival 2006;253:1428-1436.
20. Castro-Costa CM, Oriá RB, Machado-Filho JA, et al. Amyotrophic lateral sclerosis: clinical analysis of 78 cases from Fortaleza (Northeastern Brazil). Arq Neuropsiquiatr 1999;57:761-774.

21. Kleopas AK, Sherman M, Neal B, Romano GJ, Heiman-Patterson. Bipap improves survival and rate of pulmonary function decline in patients with ALS. J Neurol Sci 1999;164:82-88.

22. Jackson CE, Rosenfeld J, Moore DH, et al. A preliminary evaluation of a prospective study of pulmonary function studies and symptoms of hypoventilation in ALS/ MND patients. J Neurol Sci 2001;191:75-78.

23. Melo J, Homma A, Iturriaga E, et al. Pulmonary evaluation and prevalence of non-invasive ventilation in patients with amyotrophic lateral sclerosis: a multicenter survey and proposal of a pulmonary protocol. J Neurol Sci 1999;169:114-117.

24. Dougan CF, Connell CO, Thornton E, Young CA. Development of a patient-specific dyspnoea questionnaire in motor neurone disease (MND): the dyspnoea rating scale (MRDS). J Neurol Sci 2000;180:86-93.

25. Desport JC, Preux PM, Truong CT, Courat L, Vallat JM, Couratier P. Nutritional assessment and survival in ALS patients. Amyotroph Lateral Scler Other Motor Neuron Disord 2000;1:91-96.

26. Rowland LP, Mitsumoto H, De-Vivo DC. Doenças do neurônio motor hereditárias e adquiridas. In Merritt: Tratado de Neurologia. ed. 11. Rio de Janeiro: Ed. Guanabara Koogan, 2007:798-805.

27. Stanich P, Pereira AML, Chiappeta ALML, Nunes M, Oliveira ASB, Gabbai AA. Suplementação nutricional em pacientes com doença do neurônio motor/ esclerose lateral amiotrófica. Rev Bras de Nutri Clin 2004;19:70-78.

28. Santos DM, Sichieri R. Índice de massa corporal e indicadores antropométricos de adiposidade em adultos. Rev Saúde Pública 2005;22:163-168.

29. Frisancho RA, Flegel PN. Relative merits of old and new indices of body mass with reference to skinfold thichness. Am J Clin Nutr 1982;36:697-679.

30. Gallagher D, Visser M, Sepúlveda D, Pierson RN, Harris T, Heymsfield SB. How useful is body mass index for comparison or body fatness across age, sex, and ethnic groups? Am J Epidemiol 1996;146:228-239.

31. James WPT, Mascie-Taylor GNC, Norgan NG, Bistrian BR, Shetty PS, Ferro-Luzzi A. The value of arm circumference measurements in assessing chronic energy deficiency in Third World adults. Eu J Clin Nutr 1994;48:883-894. 